1966-02-01

\title{
X-Ray Diffraction Studies on Tin to 100 Kilobars
}

\author{
J. Dean Barnett \\ jdeanbarnett@gmail.com
}

Vern E. Bean

H. Tracy Hall

Follow this and additional works at: https://scholarsarchive.byu.edu/facpub

Part of the Astrophysics and Astronomy Commons, and the Physics Commons

\section{Original Publication Citation}

Barnett, Dean J., Vern E. Bean, and Tracy H. Hall."X-Ray Diffraction Studies on Tin to 1 Kilobars." Journal of Applied Physics 37 (1966): 875-877.

\section{BYU ScholarsArchive Citation}

Barnett, J. Dean; Bean, Vern E.; and Hall, H. Tracy, "X-Ray Diffraction Studies on Tin to 100 Kilobars" (1966). Faculty Publications. 808.

https://scholarsarchive.byu.edu/facpub/808

This Peer-Reviewed Article is brought to you for free and open access by BYU ScholarsArchive. It has been accepted for inclusion in Faculty Publications by an authorized administrator of BYU ScholarsArchive. For more information, please contact ellen_amatangelo@byu.edu. 
increases progressively as the applied stress is raised, with a total plastic strain of $\sim 160 \times 10^{-6} \mathrm{in}$./in. measured prior to fracture.

(2) A large anelastic contraction is measured at zero stress after unloading a plastically strained specimen. The extent of this recovery depends on the previously applied stress level and the number of loadunload cycles used.

(3) In the temperature range from $-196^{\circ}$ to $100^{\circ} \mathrm{C}$ the measured values of energy absorbed during fracture are larger for unnotched longitudinal specimens than for unnotched transverse specimens. The longitudinal specimens exhibit a pronounced maximum at $0^{\circ} \mathrm{C}$ in the energy-absorbed versus temperature curve, a feature which is also found in the tensile fracture-stress versus temperature curve. It is shown that the measured temperature dependence is controlled by a reversible process. The presence of a notch on the surface of the impact specimens considerably reduces the measured values of energy absorbed for both longitudinal and transverse specimens.

(4) At temperatures $>200^{\circ} \mathrm{C}$ the energy absorbed during fracture decreases to zero for both longitudinal and transverse specimens. This transition is related to permanent changes in the structure of bone caused by decomposition of the material.

\section{ACKNOWLEDGMENTS}

The authors are grateful to K. V. Vuori and S. Marquardt for experimental assistance, to Dr. J. A. Sartell for helpful discussions and to Dr. J. N. Dempsey, Director of Honeywell Research Center, for his continued interest and permission to publish.

\title{
X-Ray Diffraction Studies on Tin to 100 Kilobars*
}

\author{
J. Dean Barnett, Vern E. Bean, $\dagger$ and H. Tracy Hall \\ Departments of Physics and Chemistry, Brigham Young University, Provo, Utah
}

(Received 13 September 1965)

\begin{abstract}
The high-pressure equilibrium phase diagram of tin is investigated, and the crystal structure of Sn II at $98 \mathrm{kbar}$ and $25^{\circ} \mathrm{C}$ is shown to be body-centered tetragonal with $a=3.70 \AA, c=3.37 \AA, c / a=0.91$, and with two atoms per unit cell. The linear compressibility of white tin is given at $25^{\circ} \mathrm{C}$ up to the high-pressure transformation at $92 \mathrm{kbar}$, and the latent heat of the transformation is measured as $225 \mathrm{cal} / \mathrm{g}$-atom.
\end{abstract}

$T$

HE crystal structure of white tin with its tetrahedral coordination in a tetragonal unit cell represents an interesting example of directional bonding, and considerable interest has recently been shown in the vibrational modes of the lattice ${ }^{1-3}$ and the atomic force constants ${ }^{4}$ for this rather unique material. Somewhat related to these studies is the investigation of the polymorphic phase transitions induced by either temperature or pressure, since the mechanisms for such transitions might be explained by vibrational instabilities or anomalous changes in atomic force constants. The measurements reported here were made in order to clarify and elucidate some aspects of the high-pressure phase diagram for $\mathrm{Sn}$ and to obtain room-temperature linear compressibility data on Sn I (white tin) up to the high-pressure (Sn I-Sn II )transition.

* This work was supported by the U. S. Army Research OfficeDurham.

† Presently at Lawrence Radiation Laboratories, Livermore, California.

${ }^{1}$ C. J. Meechan, A. H. Muir, U. Gonser, and H. Wiedersich, APS Bulletin, Stanford (Dec. 1962).

2 T. Wolfram, G. W. Lehman, and R. E. DeWames, Phys. Rev. 129, 2483 (1963).

${ }^{3}$ R. E. DeWames, T. Wolfram, and G. W. Lehman, Phys. Rev. 131, 529 (1963).

4. A. Rayne and B. S. Chandrasekhar, Phys. Rev. 120, 1658 (1960).

\section{A. HIGH-PRESSURE PHASE DIAGRAM}

The measurement of a cusp in the melting curve at approximately $33 \mathrm{kbar}$ and $310^{\circ} \mathrm{C}$ by Dudley and Hall ${ }^{5}$ in 1960 was the first indication of the existence of a highpressure polymorph. Efforts by them to detect the phase line emanating from the cusp by monitoring electrical resistance failed. Kennedy and Newton, ${ }^{6}$ using a differential thermal analysis technique, confirmed the cusp and established the phase line with a negative slope of approximately $2.5^{\circ} \mathrm{C} / \mathrm{kbar}$. Stager, Balchan, and Drickamer ${ }^{7}$ measured a discontinuity in resistance at a reported pressure of 113 to $115 \mathrm{kbar}$ and $25^{\circ} \mathrm{C}$ in reasonable agreement with the extrapolated phase line of Kennedy and Newton. Stager, Balchan, and Drickamer, as well as Kaufman, ${ }^{8}$ speculated that the transformation was to a cubic phase, and thermodynamic calculations seemed to give strength to this assumption. Jamieson, ${ }^{9}$

${ }^{5}$ J. D. Dudley and H. T. Hall, Phys. Rev. 118, 1211 (1960).

${ }^{6}$ G. C. Kennedy and R. C. Newton, Solids Under Pressure (McGraw-Hill Book Company, Inc., New York, 1963), Chap. 7, p. 172.

${ }^{7}$ R. A. Stager, A. S. Balchan, and H. G. Drickamer, J. Chem. Phys. 37, 1154 (1962).

${ }^{8}$ L. Kaufman, Solids Under Pressure (McGraw-Hill Book Company, Inc., New York, 1963), Chap. 11, p. 328.

9 J. C. Jamieson, Report at the AIME meetings, Dallas (Feb. 1963) and later at the American Physical Society Meetings, Philadelphia (March 1964). 
from $x$-ray diffraction data, reported a structure determination of body-centered-cubic (bcc) for $\mathrm{Sn}$ in the region of $130 \mathrm{kbar}$ and $25^{\circ} \mathrm{C}$. Barnett, Bennion, and Hall ${ }^{10}$ working in this laboratory reported a structure determination of body-centered-tetragonal (bct) $(c / a=0.91)$ for $\mathrm{Sn}$ at $39 \mathrm{kbar}$ and $314^{\circ} \mathrm{C}$ in apparent contradiction to the work of Jamieson. Jamieson ${ }^{9}$ later reported observing the bct structure at pressures in excess of $120 \mathrm{kbar}$ at $25^{\circ} \mathrm{C}$.

A ccrrelation of these data implied the existence of either a new phase line on the phase diagram or a continuous variation of the $c / a$ ratio of the tetragonal lattice from 0.91 to 1.00 as one moves to higher pressures along the Sn I-Sn II phase line. Such a variation would be of great interest.

During the past year the pressure capabilities of the high-temperature, high-pressure, tetrahedral x-ray diffraction apparatus ${ }^{11}$ have been extended to approximately $120 \mathrm{kbar}$ by utilizing smaller anvils with wedgeshaped gaskets. ${ }^{12}$ Using this apparatus the structure of $\mathrm{Sn}$ in the region above the transition at room temperature was determined to be simple bct with a $c / a$ ratio of 0.91 , which, within experimental error, is the identical structure previously observed at $39 \mathrm{kbar}$ and $314^{\circ} \mathrm{C}$, in direct contradiction with Jamieson's work. The $\mathrm{x}$-ray powder data for one determination of the new structure are given in Table I. Three independent determinations were made, and agreement on lattice parameters was better than $0.2 \%$ when corrected to the same pressure. No diffraction lines were observed which could not be indexed, and no evidence of a cubic phase could be found. This result implies the existence of a single phase line connecting the melting curve and the room-temperature transition as originally assumed by Stager, Balchan, and Drickamer. As further support for this conclusion, the $\mathrm{Sn}$ I-Sn II phase line was followed from about $48 \mathrm{kbar}$ and $250^{\circ} \mathrm{C}$ to the room-temperature transition point by observing the Sn I (200) and (101) lines disappear and appear alternately with the Sn II (101) and (110) lines as the phase line was repeatedly

TABLE I. X-ray diffraction data for Sn II at $98 \mathrm{kbar}$ and $25^{\circ} \mathrm{C}$ indexed as a simple body-centered tetragonal lattice. ${ }^{\mathrm{a}}$

\begin{tabular}{cccrr}
\hline \hline$h k l$ & $d_{\text {cal }}$ & $d_{\text {cxp }}$ & $I_{\text {cal }}$ & $I_{\exp }$ \\
\hline 101 & 2.491 & 2.492 & 100 & 100 \\
110 & 2.614 & 2.616 & 58 & 54 \\
200 & 1.848 & 1.849 & 26 & 17 \\
002 & 1.685 & 1.681 & 7 & 7 \\
121 & 1.484 & 1.484 & 38 & 34 \\
112 & 1.416 & 1.416 & 17 & 12 \\
220 & 1.307 & 1.309 & 7 & 9 \\
202 & 1.245 & 1.244 & 12 & 8 \\
\hline
\end{tabular}

a $a=3.70 \pm 0.01 \AA ; c=3.37 \pm 0.01 \AA ; c / a=0.911$.

${ }^{10} \mathrm{~J}$. D. Barnett, R. B. Bennion, and H. T. Hall, Science 141 1041 (1963).

${ }^{11}$ J. D. Barnett and H. T. Hall, Rev. Sci. Instr. 35, 175 (1964).

12 V. E. Bean, Master's thesis, Brigham Young University (1964). traversed. As an additional indication, while at a pressure above the room-temperature transition point, the temperature was increased slowly to a nominal $500^{\circ} \mathrm{C}$. No change was observed in the dominant features of the x-ray pattern.

In view of these results and the fact that Jamieson observed the bct structure at much higher pressures, we propose the simple diagram of Fig. 1 as the equilibrium phase diagram of $\mathrm{Sn}$ with no other phase lines existing in the pressure-temperature region of 1 bar to $100 \mathrm{kbar}$ and $25^{\circ}$ to $500^{\circ} \mathrm{C}$. The measurements of Jamieson might be due to preferential orientation of the sample crystallites in his uniaxial (Bridgman anvil) apparatus. If the transformation mechanism is that described by Musgrave, ${ }^{13}$ the preferred orientation in the Sn I phase previous to the transformation reported by Jamieson ${ }^{9}$ might give rise to an altered $c / a$ ratio in Sn II due to the anisotropic stress distribution produced

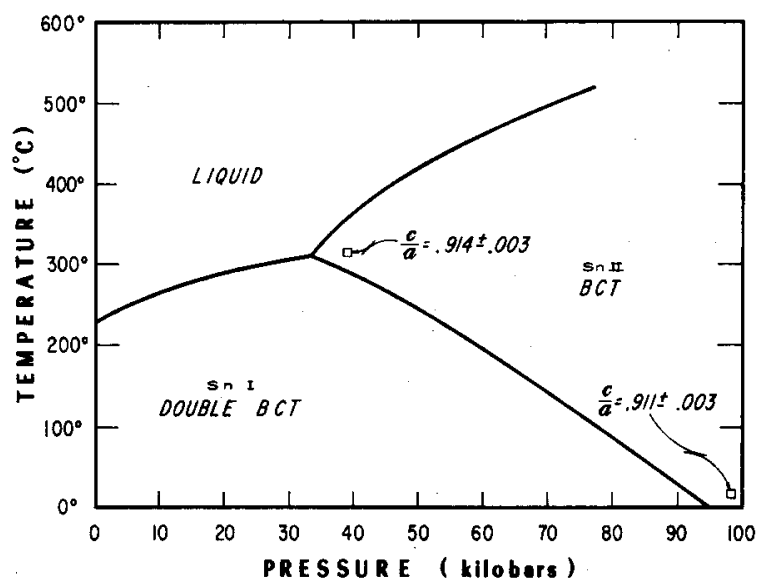

FIG. 1. Phase diagram of $\mathrm{Sn}$ to $100 \mathrm{kbar}$ showing points where bct structure determinations have been made.

during the transformation. It is also possible that a stress-stabilized bcc phase might exist, due to stresses caused by this same preferential orientation. Such a phenomenon would be interesting and significant in and of itself. Preferred orientation and shear stress is greatly minimized in a tetrahedral apparatus due to the threedimensional character of the applied force. Furthermore, the Sn powder used in the present experiment was intimately mixed with micron-sized polyethylene powder in a volume ratio of one to four to assure more uniform pressure distribution among the individual particles. Evidence of the random crystallite orientation in the tetrahedral apparatus is found in the good agreement of the calculated and measured relative line intensities in both the $\mathrm{Sn} I$ and $\mathrm{Sn}$ II diffraction patterns.

In Fig. 1 the phase line is drawn to a point at $92 \mathrm{kbar}$ and $25^{\circ} \mathrm{C}$, a pressure value lower than that previously reported. A determination of this pressure was made utilizing a sodium chloride internal standard intimately

${ }^{13}$ M. J. P. Musgrave, J. Phys. Chem. Solids 24, 557 (1962). 
mixed with the Sn. A measurement of the lattice parameter of sodium chloride by $\mathrm{x}$-ray means determined the pressure by reference to the compressibility data theoretically determined by Decker ${ }^{14}$ for this purpose. This lowering of the pressure value assigned to the Sn transition at room temperature is consistent with measurements of other fixed calibration points made in this laboratory ${ }^{15}$ by the same technique and represents a significant decrease in the values assigned to these high pressure transitions.

\section{B, COMPRESSIBILITY DATA}

The lattice parameters of Sn I at pressures just below the transition and the linear compressibility in the two crystallographic directions at that point have bearing on the stability of the lattice, the mechanism for the transformation, and the latent heat of the transformation. Datum points obtained for the linear compression of Sn I as measured by $\mathrm{x}$-ray techniques are shown in Fig. 2 for pressures up to the transition at $92 \mathrm{kbar}$ and $25^{\circ} \mathrm{C}$. The last datum point shown at $94 \mathrm{kbar}$ was obtained when a sizable portion of the sample had transformed. The Sn I-II and II-I transitions are somewhat sluggish at room temperature but are very rapid at temperatures above $150^{\circ} \mathrm{C}$. At the higher temperature the I-I transition line should represent true equilibrium. Near room temperature the line may deviate from true equilibrium by as much as $\pm 3 \mathrm{kbar}$, the approximate region of indifference.

The solid curves are second-order polynomial equations in which the linear coefficient was taken from the elastic constants data of Rayne and Chandrasekhar, ${ }^{3}$ thus establishing the initial slope. Their data agreed well with the initial slope of Bridgman's single-crystal linear compressibility data to $30 \mathrm{kbar}^{16}$ shown as solid circles in Fig. 2. The quadratic coefficient was determined by a least-square fit to the high-pressure data given herein. The average deviation of the datum points from these curves is less than the $0.2 \%$ probable error estimated for an $x$-ray volume measurement in our apparatus on a material such as $\mathrm{Sn}$. The expressions for the linear compressions (where the pressure $P$ is given in bars) are

$$
\Delta a / a=5.80 \times 10^{-7} P-1.15 \pm 0.20 \times 10^{-12} P^{2},
$$

and

$$
\Delta c / c=6.63 \times 10^{-7} \mathrm{P}-1.20 \pm 0.20 \times 10^{-12} \mathrm{P}^{2}
$$

It is interesting to note that the $c / a$ ratio of $\mathrm{Sn} \mathrm{I}$ changes by less than $0.1 \%$ from 1 bar to $90 \mathrm{kbar}$, and

${ }^{14}$ D. L. Decker, J. Appl. Phys. 36, 157 (1965).

${ }_{15} \mathrm{R}$. N. Jeffery, Master's thesis, Brigham Young University (1965) (to be published).

${ }_{10}$ P. W. Bridgman, Proc. Am. Acad. Arts Sci. 77, 189 (1949).

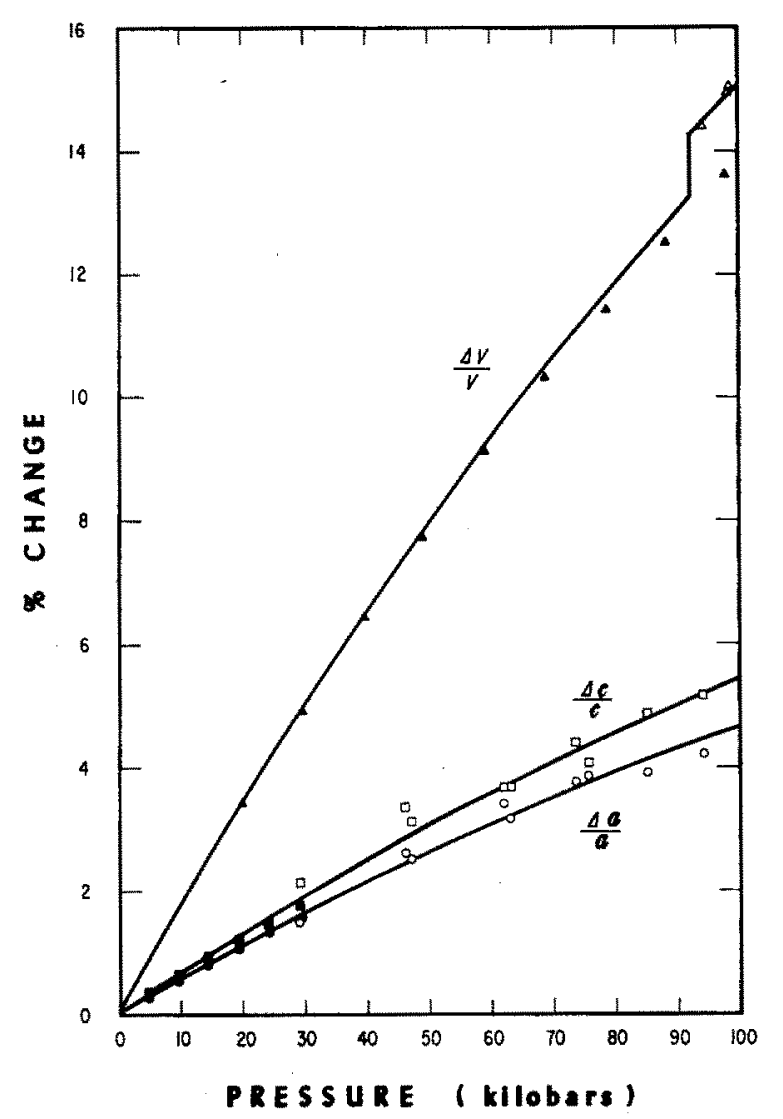

Fig. 2. Linear and volume compressions for $\mathrm{Sn}$ (at $25^{\circ} \mathrm{C}$ ) to $100 \mathrm{kbar}$ compared with Bridgman's data. O measured $a$-axis compressions; $\square$ measured $c$-axis compressions; $\bullet B$ ridgman's $a$-axis compressions, Ref. 16; Bridgman's $c$-axis compressions, Ref. 16; $\Delta$ Bridgman's volume compressions, Ref. 17; $\Delta$ measured volume compressions for Sn II phase. The solid lines are quadratic expansions using initial slopes from elastic constants data as discussed in text.

the $c / a$ ratio of $\mathrm{Sn}$ Ir changes by less than $0.5 \%$ between 40 and $100 \mathrm{kbar}$. The small change in this particular parameter implies a strong influence in both structures of the next-nearest atomic coordination atom, which is in the $c$ direction. The volume compression curve shown in Fig. 2 is obtained analytically from the linear compression equations. Bridgman's ${ }^{17} 100-\mathrm{kbar}$ volume compression data are shown for comparison as solid triangles. Agreement here is consistent with the accuracy of the pressure calibration used in each case.

From Fig. 1 we obtain a slope of -170 bars $/{ }^{\circ} \mathrm{C}$ for the Sn I-Sn II phase line at room temperature and at $92 \mathrm{kbar}$ and a volume compression of $1.1 \pm 0.2 \%$ at the transition from Fig. 2. Using these data the Clapeyron equation yields a latent heat of $225 \mathrm{cal} / \mathrm{g}$-atom at $25^{\circ} \mathrm{C}$ and $92 \mathrm{kbar}$ with an estimated accuracy of \pm 45 $\mathrm{cal} / \mathrm{g}$-atom.

\footnotetext{
${ }^{17}$ P. W. Bridgman, Phys. Rev. 60, 351 (1941).
} 